\title{
UV-sensitivity of free and immobilized on chitosan matrix proteases ${ }^{\dagger}$
}

\author{
Svetlana Pankova ${ }^{1 *}$, Marina Holyavka ${ }^{1}$, Valeriy Artyukhov ${ }^{1}$ \\ 1 Department of Biophysics and Biotechnology, Voronezh State University, Voronezh Oblast 394036, Russia; \\ holyavka@rambler.ru (M.H.); artyukhov@bio.vsu.ru (V.A.) \\ * Correspondence: sazykina.93@mail.ru \\ + Presented at 1st International Electronic Conference on Catalysis Sciences, 10-30 November 2020; \\ Available online: https://eccs2020.sciforum.net
}

Published: 10 November 2020

\begin{abstract}
UV irradiation is an essential factor in natural and artificial climate in modern environmental conditions, which has a constant effect on living systems. Collagenase, bromelain, ficin, papain («Sigma-Aldrich») and trypsin («MP biomedicals») were the objects of this study. The substrate for hydrolysis was BSA («Sigma-Aldrich»), the carriers for immobilization were chitosans $(<100,200$ and $350 \mathrm{kDa})$ and chitosan succinate («Bioprogress»). The protease immobilization was carried out by the adsorption. The determination of the protein amount in samples and their catalytic activity was carried out by the modified Lowry method. UV irradiation of proteases was performed using doses 151-6040 J/m². By the degree of photosensitivity, hydrolases can be arranged in the next row: collagenase $\rightarrow$ bromelain $\rightarrow$ ficin $\rightarrow$ papain $\rightarrow$ trypsin. Adsorption on a chitosan and succinate of chitosan leads to an increase in the stability to ultraviolet light of heterogeneous (immobilized) biocatalysts compared to free enzymes. Photoprotective effect of the chitosan may be due to the following reasons: enzyme interact with the chitosan to form photo resistant complexes; chitosan screen active free-radicals, preventing the photooxidation of a certain number of amino acids, including the active centers of the studied enzymes under the influence of UV irradiation.
\end{abstract}

Keywords: collagenase; bromelain; ficin; papain; trypsin; chitosan; chitosan succinate; UV irradiation

\section{Introduction}

UV radiation is a permanent factor in the external environment, absorbed in living cells mainly by proteins and nucleic acids. The main result of the impact of UV radiation on proteins is photodenaturation of them. In some cases, the UV irradiation leads to the activation of enzyme molecules. It is proved that the major protein chromophores are the aromatic amino acid residues, especially tryptophan and to a much lesser extent tyrosine and phenylalanine, and sulfur-containing amino acid residues. These amino acids and cystine are responsible for the functional activity of the absorption of light quanta by protein macromolecules. This is evidenced by the coincidence of the spectra of proteins action photoinactivating with their absorption spectra [1-4].

Despite wide photochemical and photobiological works, many questions remain outstanding of biological effect of UV radiation on living organisms, and in particular, the specific characteristics of the different areas of action of UV radiation on plant enzymes. UV rays have a high biological activity, they are extremely diverse applications in medicine, industry, agriculture. In connection with this 
work, which aimed at studying the biological effect of ultraviolet light on the study of UV-induced changes in the structural and functional characteristics of enzymes, remain relevant $[1,3]$.

Research on the development of high stability heterogeneous preparations based on immobilized enzymes are gaining popularity and necessity. At fixation of the enzyme to insoluble carrier heterogeneous biocatalysts are obtained which have the following advantages: increases not only the stability, but also the efficiency of the medicament by controlling the reaction process. For the immobilized enzymes number of possible inactivating mechanisms (such as UV radiation, temperature) is substantially less than in the case of soluble proteins.

Proteases are widely used in the pharmacy and food industry. They amount about $60 \%$ of the global sales of enzymes. Bromelain, papain and ficin are the most studied for meat tenderization and have the GRAS status. Various proteases (unclude cysteine proteases and trypsin) use in the treatment of skin lesions, because they act as antimicrobial agents.

Our aim was to study the effects of ultraviolet irradiation on photomodulation of collagenase, bromelain, ficin, papain, trypsin activity, both free and adsorbed on chitosan and succinate of chitosan.

\section{Methods}

Collagenase, bromelain, ficin, papain (Sigma), trypsin («MP biomedicals») were chosen as objects of study. bovine serum albumin (BSA) was used as a substrate for hydrolysis. Chitosans (< 100, 200 and $350 \mathrm{kDa}$ ) and chitosan succinate («Bioprogress») was used as a carrier for immobilization.

Immobilization of proteases on the chitosan matrix was carried out by the adsorption [5]. The determination of the protein amount in samples and their catalytic activity was carried out by the modified Lowry method. The enzyme quantity hydrolizing $1 \mu \mathrm{M}$ of bovine serum albumin (BSA) per 1 min was taken as a unit of catalytic activity [6].

UV irradiation of the free and immobilized enzymes was carried out using a mercury-quartz lamp of the DRT400 type through a UVS-1 filter (transmission band of 240-390 nm) in a thermostated cell $\left(20 \pm 1^{\circ} \mathrm{C}\right)$ by their continuous mixing with a magnetic stirrer.

\section{Results and Discussion}

By the degree of photosensitivity, hydrolases can be arranged in the next row: collagenase $\rightarrow$ bromelain $\rightarrow$ ficin $\rightarrow$ papain $\rightarrow$ trypsin (Figure 1-5). Adsorbtion on a chitosan $(<100,200$ and 350 $\mathrm{kDa}$ ) and succinate of chitosan leads to an increase in the stability of biocatalysts to ultraviolet.

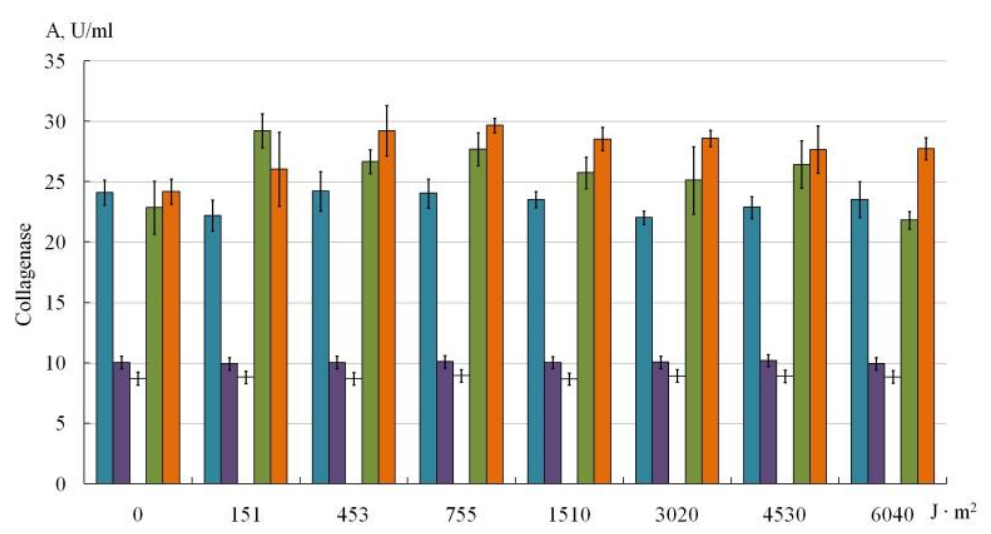

Figure 1. Effect of ultraviolet irradiation on the catalytic activity of collagenase. In the graph, blue color is used for the collagenase in solution, violet for the collagenase adsorbed on low molecular weight chitosan $(<100 \mathrm{kDa})$, white for that adsorbed on succinate of chitosan, green for the collagenase adsorbed on medium molecular weight chitosan $(200 \mathrm{kDa})$, orange or the collagenase adsorbed on high molecular weight chitosan (350 kDa). 


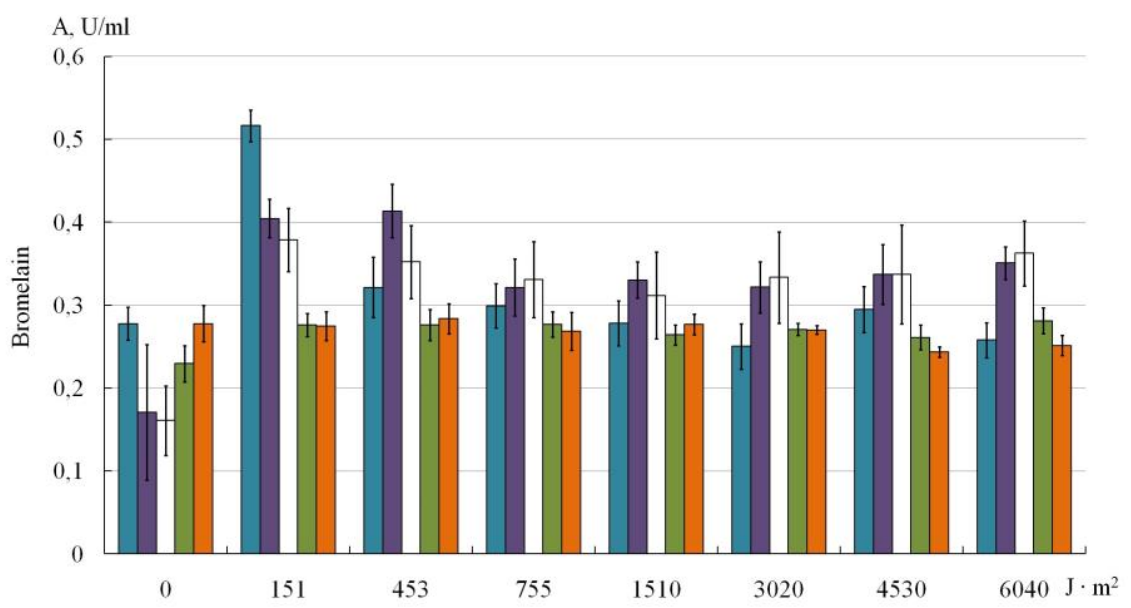

Figure 2. Effect of ultraviolet irradiation on the catalytic activity of bromelain. In the graph, blue color is used for the bromelain in solution, violet for the bromelain adsorbed on low molecular weight chitosan $(<100 \mathrm{kDa})$, white for that adsorbed on succinate of chitosan, green for the bromelain adsorbed on medium molecular weight chitosan $(200 \mathrm{kDa})$, orange or the bromelain adsorbed on high molecular weight chitosan (350 kDa).

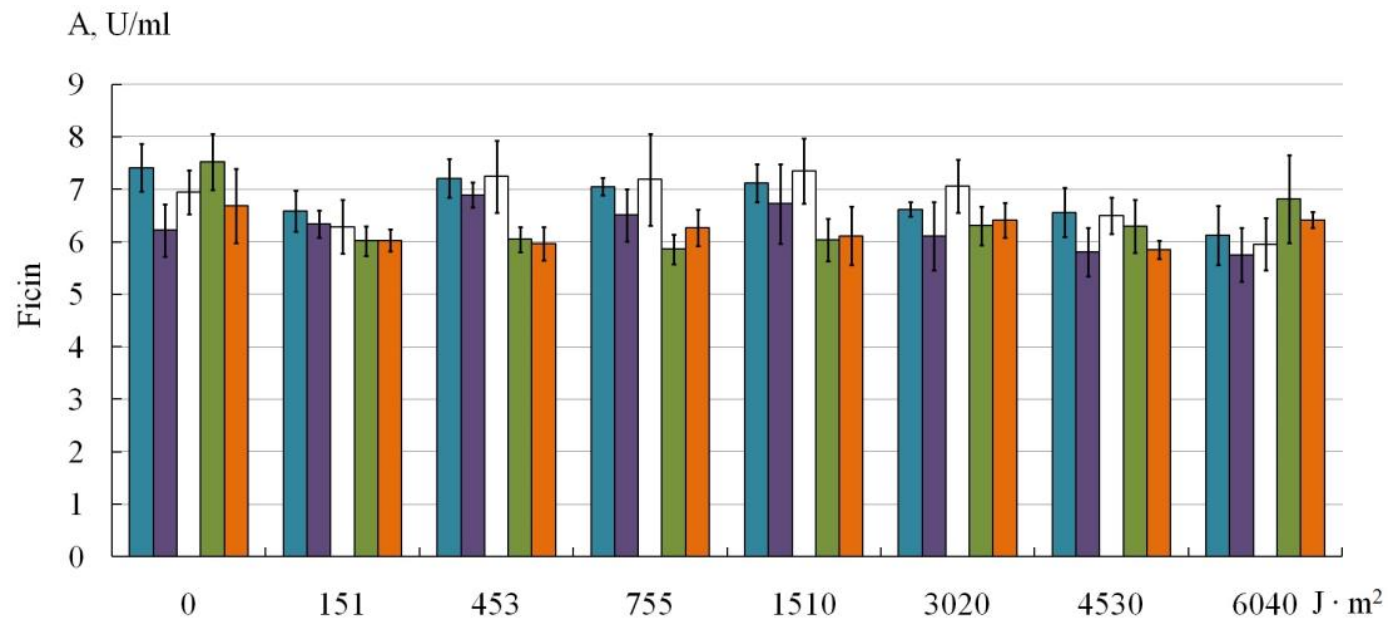

Figure 3. Effect of ultraviolet irradiation on the catalytic activity of ficin. In the graph, blue color is used for the ficin in solution, violet for the ficin adsorbed on low molecular weight chitosan $(<100$ $\mathrm{kDa})$, white for that adsorbed on succinate of chitosan, green for the ficin adsorbed on medium molecular weight chitosan $(200 \mathrm{kDa})$, orange or the ficin adsorbed on high molecular weight chitosan (350 kDa). 


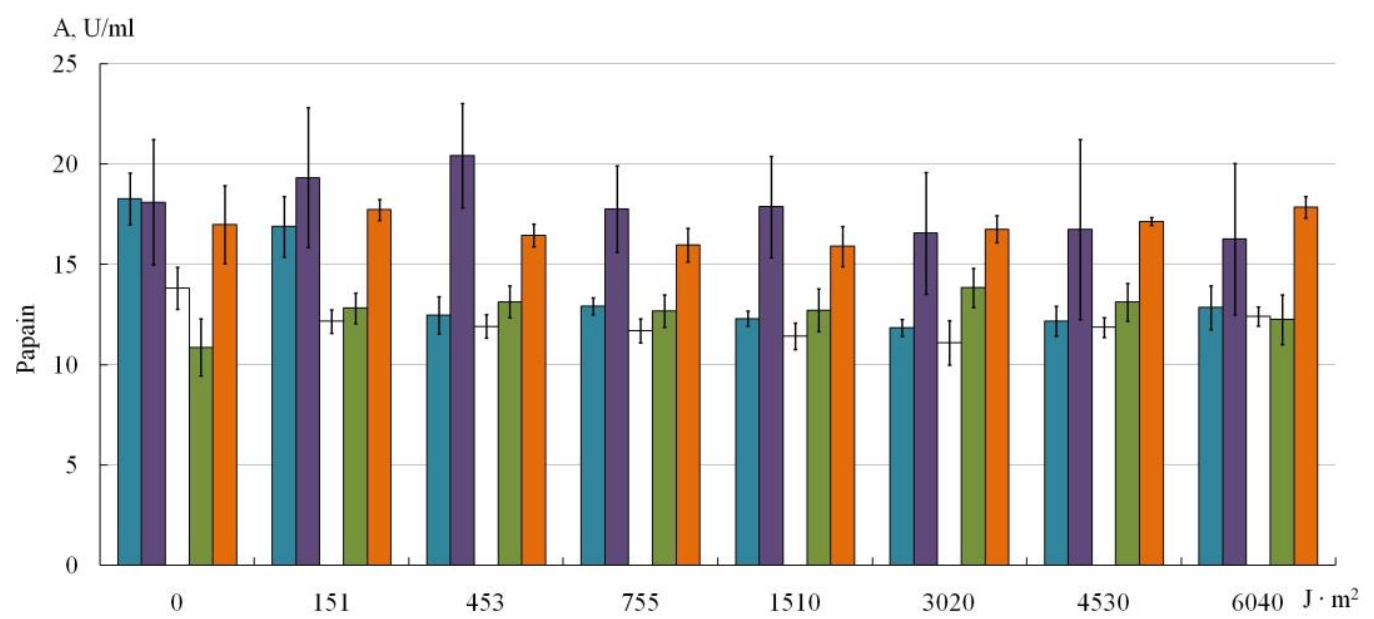

Figure 4. Effect of ultraviolet irradiation on the catalytic activity of papain. In the graph, blue color is used for the papain in solution, violet for the papain adsorbed on low molecular weight chitosan $(<$ $100 \mathrm{kDa}$ ), white for that adsorbed on succinate of chitosan, green for the papain adsorbed on medium molecular weight chitosan $(200 \mathrm{kDa})$, orange or the papain adsorbed on high molecular weight chitosan (350 kDa).

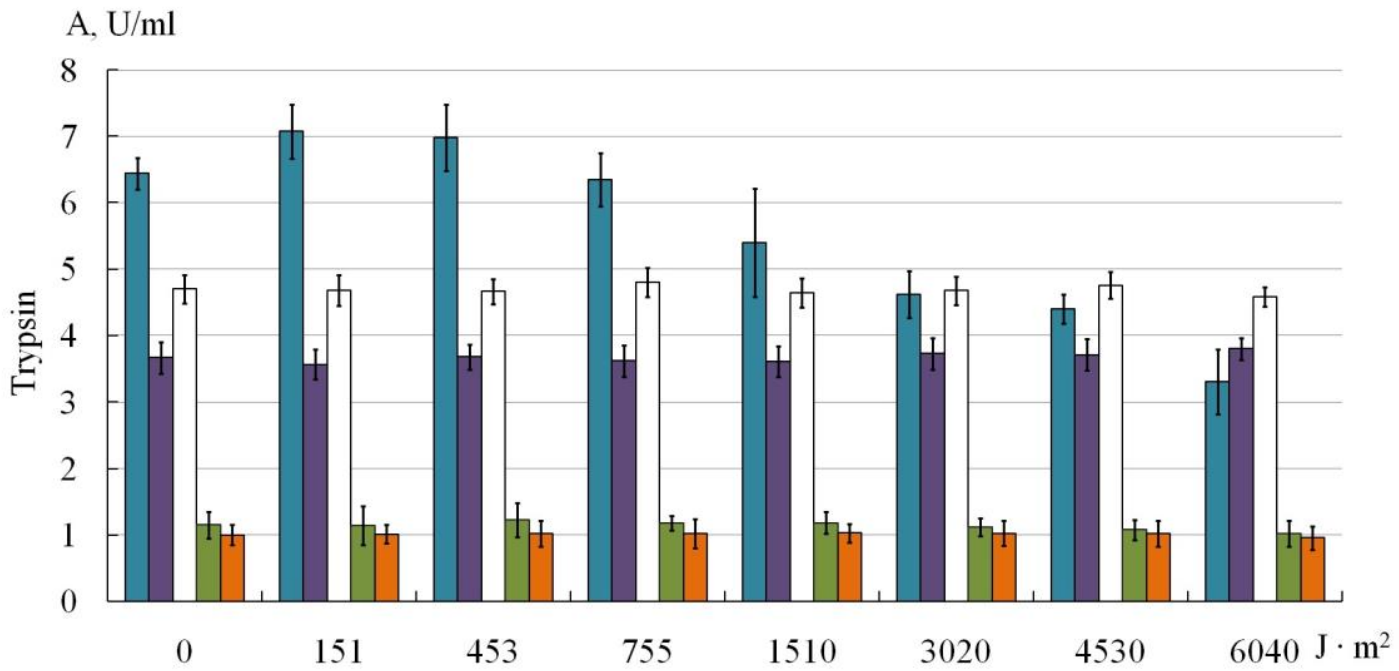

Figure 5. Effect of ultraviolet irradiation on the catalytic activity of trypsin. In the graph, blue color is used for the trypsin in solution, violet for the trypsin adsorbed on low molecular weight chitosan (< $100 \mathrm{kDa}$ ), white for that adsorbed on succinate of chitosan, green for the trypsin adsorbed on medium molecular weight chitosan $(200 \mathrm{kDa})$, orange or the trypsin adsorbed on high molecular weight chitosan (350 kDa).

\section{Conclusions}

The ultraviolet exposure changes more likely the catalytic activity of protease in solution than adsorbed. In comparison with free enzymes immobilization leads to an increase in the stability of biocatalysts to UV irradiation. The chitosan matrix probably plays the role of photoprotector for immobilized : collagenase, bromelain, ficin, papain and trypsin. Our data indicate photoprotective effects of chitosans $(<100,200$ and $350 \mathrm{kDa})$ and chitosan succinate, which may be due to the following reasons: 1 ) chitosan reacts with the enzyme molecule forming a more photoresistant complex than the native protein molecule; 2)chitosan probably binds and/or shields the active photoproducts of the free radical nature, preventing photooxidation of a certain number of ficinamino acids under UV irradiation. 
Author Contributions: Authors have equal contributions in the preparation and writing of the article.

Funding: This work was financially supported in the form of a grant from the President of the Russian Federation for state support to young Russian scientists - doctors of sciences (MD-1982.2020.4. Agreement 07515-2020-325).

Conflicts of Interest: The authors declare no conflict of interest. The funders had no role in the design of the study; in the collection, analyses, or interpretation of data; in the writing of the manuscript, or in the decision to publish the results.

\section{References}

1. Folgosa F., Camacho I., Penas D., Guilherme M., Fróis J., Ribeir P.A., Tavares P., Pereira A.S., UV irradiation effects on a DNA repair enzyme: conversion of a $[4 \mathrm{Fe}-4 \mathrm{~S}]^{2+}$ cluster into a $[2 \mathrm{Fe}-2 \mathrm{~S}]^{2+}$, Radiat. Environ. Biophys. 2015, 54, 111-121.

2. Ring J., Atopic Dermatitis - Eczema, Springer, Cham, 2016

3. Bintsis T., Litopoulou-Tzanetaki E., Robinson R.K., Existing and potential applications of ultraviolet light in the food industry - a critical review, J. Sci. Food Agric. 2000, 80,637-645.

4. Mohr H., Gravemann U., Bayer A., Müller T.H., Sterilization of platelet concentrates at production scale by irradiation with short-wave ultraviolet light, Transfusion 2009, 49, 956-1963.

5. Trizna E., Diana B., Kholyavka M., Sharafutdinov I., Hairutdinova A., Khafizova F., Soluble and immobilized papain and trypsin as destroyers of bacterial biofilms, Genes to Cells 2016, 10, 106-112.

6. Holyavka M., Pankova S., Koroleva V., Vyshkvorkina Yu., Lukin A., Kondratyev M., Artyukhov V., Influence of uv radiation on molecular structure and catalytic activity of free and immobilized bromelain, ficin and papain, Journal of Photochemistry and Photobiology B: Biology 2019, 201, 111681.

(c) (i

(C) 2020 by the authors; licensee MDPI, Basel, Switzerland. This article is an open access article distributed under the terms and conditions of the Creative Commons Attribution (CC-BY) license (http://creativecommons.org/licenses/by/4.0/). 